\title{
Investigating the effectiveness of adding microcurrent therapy to a traditional treatment program in myofascial pain syndrome in terms of neck pain and function
}

\author{
DOI: https://doi.org/10.5114/pq.2020.96421
}

\author{
Kadrya H. Battecha ${ }^{1,2}$, Dalia M. Kamel ${ }^{3}$, Sayed A. Tantawy ${ }^{4,5}$ \\ ${ }^{1}$ Department of Physical Therapy, Faculty of Applied Medical Sciences, Umm Al-Qura University, Mecca, Saudi Arabia \\ ${ }^{2}$ Department of Basic Science, Faculty of Physical Therapy, Cairo University, Cairo, Egypt \\ ${ }^{3}$ Department of Physical Therapy for Women's Health, Faculty of Physical Therapy, Cairo University, Cairo, Egypt \\ ${ }^{4}$ Department of Physiotherapy for Integumentary Problems, Faculty of Physiotherapy, Deraya University, Minya, Egypt \\ ${ }^{5}$ Department of Physiotherapy, Centre of Radiation, Oncology and Nuclear Medicine, Cairo University, Cairo, Egypt
}

Abstract

Introduction. To investigate the effect of microcurrent on pain, pain threshold, range of motion, neck muscle strength, and neck function.

Methods. It is a pilot study involving 28 female subjects (aged 18-24 years) complaining of neck pain due to active unilateral trigger points in upper trapezius muscle. The subjects were randomly assigned to 2 groups: group I $(n=15)$ received microcurrent (frequency: $20 \mathrm{~Hz}$, intensity: 25-30 $\mathrm{A}$ ) and traditional treatment in the form of stretching exercise for upper fibre of trapezius, isometric strengthening exercise, ischaemic compression technique; group II $(n=13)$ received only traditional treatment. All subjects received 2 sessions per week for 3 weeks.

Results. There was a significant improvement $(p<0.05)$ in cervical range of motion, pain level, neck disability index, and pain threshold in both treatment groups. Isometric muscle strength was significantly increased $(p<0.05)$ in group I, with no significant $(p>0.05)$ difference in group II. Group I showed a more significant effect in all measured variables than group II. Neck disability index and muscle strength presented a significant change $(p<0.05)$ with respect to group and time interaction.

Conclusions. Microcurrent therapy added to traditional treatment increased the effectiveness of myofascial pain syndrome treatment as compared with traditional treatment alone.

Key words: microcurrent, myofascial pain syndrome, trigger points, upper trapezius, neck pain

\section{Introduction}

Neck pain is the most common problem that can be seen in myofascial trigger point syndrome. Neck pain found to affect $60-80 \%$ of employees, which results in significant social, psychological, and economic burdens. It is associated with headache and pain radiating into the arm and upper back, and its occurrence is higher in women (15\%) than men (9\%) [1]. Women have the highest incidence at the age of 45 and men at the age of 60 [2].

Myofascial pain syndrome is characterized by local pain originating from hyperirritable palpable spots located within taut bands of skeletal muscles, known as myofascial trigger points (MTrPs) [3]. MTrPs have 2 important characteristics: referred pain and muscle twitch. They also have motor, sensory, and autonomic features. The motor features of MTrPs may include disturbed motor function, muscle weakness, muscle stiffness, and restricted range of motion (ROM) [2]. Sensory aspects include local tenderness, referral of pain, paraesthesia, and numbness, while autonomic aspects include sleep disturbance [4].

In all cases, MTrPs are associated with areas in a muscle that have stiff, tender nodules during palpation. This stiffness might arise from hyper-contracture of the sarcomere in this area [5]. Muscle hyper-contracture is consistent with sustained sarcoplasmic reticulum calcium release due to intense neural activation and potential generation of action [6]. Other pathological findings associated with sustained hypercontraction are sarcomere shortening, protein degradation, and myofiber and mitochondrial swelling; all are consistent with metabolic stress, reduced blood flow, and adenosine triphosphate (ATP) depletion [6]. In addition, cell stress triggers the release of myokines, inflammatory cytokines, and neurotransmitters that undoubtedly contribute to these MTrPs and myofascial pain syndrome [7].

Clinically, MTrPs are defined as active or latent. Active MTrPs are recognized as eliciting spontaneous pain, referred pain, motor and/or autonomic symptoms on palpation [8]. In turn, latent MTrPs upon palpation/compression lead to pain, a local twitch response, and referred pain [9].

There are several causes and risk factors that result in MTrPs, the most common ones being direct or indirect trauma, spine pathology, exposure to cumulative and repetitive strain, such as with tennis players, postural dysfunction like sitting on a chair with poor back support, and factors related to lifestyle, as lack of exercises $[4,6]$.

There are many treatment modalities to manage MTrPs, such as injections, drugs, dry needle, manual therapy, and electrotherapy. Manual therapy is one of the most effective treatments; it involves different skilled hands- and fingers-on techniques directed to the body of the patient $[10,11]$. Several manual techniques are used to relieve MTrPs, such as

Correspondence address: Dalia M. Kamel, Department of Physical Therapy for Women's Health, Faculty of Physical Therapy, Cairo University, 2 Ahmed Ezzat st, Dokki, Giza, Cairo, Egypt, e-mail: dr_daliakamel@cu.edu.eg

Received: 02.01.2020

Accepted: 21.03 .2020

Citation: Battecha KH, Kamel DM, Tantawy SA. Investigating the effectiveness of adding microcurrent therapy to a traditional treatment program in myofascial pain syndrome in terms of neck pain and function. Physiother Quart. 2021;29(1):17-23; doi: https://doi.org/10.5114/ pq.2020.96421. 
manipulation, mobilization, static stretching, muscle energy techniques, and ischaemic compression. Ischaemic compression is sustained slow progressive strong pressure on the painful area of the trigger point to eliminate pain and decrease tension in the muscle through reperfusion and transient blood flow occlusion [12]. It is performed by compressing the trigger points with tolerable pain intensity using thumb pressure or a pressure algometer, and as the degree of pain decreases, the intensity of compression is increased simultaneously [12].

Electrical stimulation is a modality that can be used with MTrPs, as it reduces pain, induces muscle stimulation and stimulation of denervated muscles [13]. Recently, it has been demonstrated that mechanical stimulation of MTrPs can induce central sensitization mechanisms in healthy subjects [14]. Electrotherapeutic modalities such as interferential currents, magnetic stimulation, laser therapy, and ultrasound therapy are the most common modalities that can be used [15].

Microcurrent electrical stimulation is a non-invasive electrotherapeutic modality that can be applied to control acute and chronic pain, as well as accelerate healing. With subsensory current provided to the tissue in a millionth of an ampere, intensities are achieved of 1-999 $\mu \mathrm{A}$. Microcurrent increases ATP concentration and membrane transport, and enhances protein synthesis [16]. It has also been reported to decrease inflammation, swelling, oedema, and increase ROM, strength, and muscle relaxation $[16,17]$.

Therefore, this study was performed to investigate the effect of microcurrent therapy on pain intensity, pressure pain threshold, neck ROM, neck muscle strength, and neck function. It also aimed to verify if there was a difference between using traditional treatment alone and using microcurrent therapy combined with traditional treatment in all measured variables.

\section{Subjects and methods}

\section{Subjects}

The study involved 28 female students selected from Umm Al-Qura University who complained of neck pain due to active unilateral MTrPs in the upper trapezius muscle. The inclusion criteria were as follows: age ranging from 18 to 24 years, body mass index $<25$, chronic neck pain for $>3$ months, pain intensity of $>4$ on the visual analogue scale, presence of a palpable nodule during examination, presence of a tender area during palpation in addition to limited neck extension and side bending ROM.

Participants were excluded if they had a history of head trauma, neck or shoulder operation, cervical spondylolisthesis, cervical neuropathy, cervical stenosis, fibromyalgia, rheumatoid arthritis, temporomandibular joint dysfunction, longterm steroid use, or use of any analgesic, anti-inflammatory drugs, or any medications that alter muscle tone over the preceding 24 hours.

The subjects were randomly assigned to 2 groups: group I (study group) received microcurrent (frequency: $20 \mathrm{~Hz}$, intensity: 25-30 $\mu \mathrm{A}$, duration: 9 minutes) combined with traditional treatment (stretching exercise for upper fibre of trapezius, isometric strengthening exercise, ischaemic compression technique); group II (control group) received traditional treatment only. Each treatment group received 2 sessions per week for 3 weeks. All participants were given a full explanation of the treatment protocol.

\section{Evaluation procedures}

\section{Pain assessment}

Pain intensity was subjectively measured with the Patient-Reported Outcomes Measurement Information System (PROMIS) form 3a, which is effective, reliable, and valid [18]. It includes 3 questions about pain intensity in the past 7 days and each question has a score from 1 to 5 , with 1 standing for no pain and 5 for very severe pain.

As an objective method, a pressure algometer was used (Force One Gauge, model FDI, Wagner Instruments, Greenwich, USA). The device serves to identify the pressure and force amount, eliciting pressure pain thresholds [19]. Pressure algometers are employed for pain threshold evaluation, therapeutic effects determination, and follow-up treatment surveys in many musculoskeletal diseases [20] and specifically in myofascial syndrome [21]. They have high inter-rater reliability in MTrPs assessment [22]. The algometer registers the force applied to a tissue in terms of kilograms per square centimetre. In the present study, the subjects were positioned comfortably, and the painful side and site were identified. The site was palpated to determine the presence of MTrPs in the upper trapezius. The palpated trigger points were marked with a skin marker. The pressure algometer probe was placed on the trigger point and a constant vertical pressure was applied to the site. The subject was instructed to express pain by raising their hand when only slight pain was felt; until then, the pressure was increased at a constant rate. The procedure was performed 3 times and the average value was recorded [12]. Patients were evaluated twice, before and after the 3 weeks of treatment.

\section{Trigger point assessment}

Trigger points were diagnosed while the subject was sitting, by palpation of the upper trapezius muscle along its axis with a thumb, from its origin in the occipital protuberance to its insertion at the medial border of the lateral acromion process. The detection of a trigger point depended on the diagnostic criteria, which were the presence of a taut band, tenderness at it, referred pain, local twitching response, and jump sign $[2,12]$.

\section{Neck function}

It was measured by using the neck disability index (NDI), which is commonly applied as a self-reported measure for patients with neck pain symptoms and their effect on activities and functions. NDI has 4 items related to subjective symptoms and 6 items related to activities of daily living. The answers are expressed on a 6-point scale, ranging from 0 (no disability) to 5 (full disability), and the numeric responses for each item were summed to form a score varying from 0 to 50 [23]. NDI has been shown to be reliable and valid in many patient populations [24].

\section{Neck muscle strength}

The isometric strength was measured by a multi-cervical unit device (BTE Technologies Inc., Hanover, USA), which is a biomechanical system developed specifically to measure the cervical isometric strength [25]. The multi-cervical unit system consists of an adjustable height seat, armrest, lumbar support, and armchair that can rotate $90^{\circ}$ to measure neck lateral flexion. It has a shoulder restraint system which iso- 
lates the cervical spine from the thoracic spine to eliminate any errors. There is also a unique head system assembly (inner and outer one) to permit the head to move safely. The inner brace is moveable and used during measuring head flexion, extension, and lateral rotation; it can insert a load cell in it to measure isometric head strength. The load cell is connected to a computer that collects the isometric strength automatically [26].

\section{Neck range of motion}

ROM was measured by a cervical ROM device, which is reliable in all neck movement directions [27]. The device was applied to the head, aligning on ears and the nose, and was fixed to the head by a strap. The measurement was taken while the subject was in a sitting position. Cervical ROM was collected for rotation, flexion/extension, and lateral flexion. The device had 3 separate inclinometers, calibrated to 0 by a magnetic neck brace: the first inclinometer in the transverse plane for rotation, the second in the sagittal plane for flexion/extension, and third inclinometer in the frontal plane for lateral flexion [28].

\section{Treatment procedures}

\section{Microcurrent electrical stimulation}

While the subject was in a prone position, the microcurrent electrical stimulation device was applied per skin in 2 phases. In phase 1 (trigger method), it was applied perpendicular and in slight compression on each trigger point for 3 minutes; in phase 2 (relaxation method), it was applied by manual scanning in the transfer technique on the upper fibres of the trapezius muscle for 3 minutes. A frequency of $20 \mathrm{~Hz}$ and intensity of 25-30 $\mu \mathrm{A}$ were used, depending on the subject's tolerance. The whole session took 9 minutes. This application only involved group I (study group), 2 times per week for 3 weeks.

\section{Traditional treatment}

Ischaemic compression in the form of sustained pressure was applied for 60 seconds twice, with a 30 -second rest in between, while the subjects were in a sitting position. It was exerted by a thumb on the painful area, while applying slow progressive pressure by the other thumb and gradually increasing pressure as the pain decreased [29]; the procedure was performed 3 times.

Stretching and strengthening exercise, as well as stretching exercise for trapezius upper fibres, lasting for 15-20 seconds, were repeated 3 times. Then, isometric strengthening exercise followed, giving maximum resistance for head extension and neck side flexion. Each position was maintained for $10-15$ seconds and repeated 5 times. The application of tra- ditional treatment involved both groups of the study, 2 times per week for 3 weeks.

\section{Statistical analysis}

All the collected data were tabulated and exported to the SPSS software (Statistical Package for the Social Sciences) version 23 for analysis. In addition to descriptive statistics, the Wilcoxon test was used to compare pre- and posttreatment pain scores, pressure pain thresholds, and NDI values within groups. The Mann-Whitney $U$ test determined differences between pre- and post-treatment pain scores, pressure pain thresholds, and NDI values between groups. For cervical ROM and isometric muscle strength, paired and unpaired $t$-test was used to detect differences within and between groups, respectively. Two-way ANOVA was applied to assess the group-time interaction for all dependent variables. The Shapiro-Wilk test served to verify data normality for both groups.

\section{Ethical approval}

The research related to human use has complied with all the relevant national regulations and institutional policies, has followed the tenets of the Declaration of Helsinki, and has been approved by the authors' institutional review board or an equivalent committee.

\section{Informed consent}

Informed consent has been obtained from all individuals included in this study.

\section{Results}

A total of 28 subjects participated in the study, with mean age of $21.04 \pm 1.3$ years, weight of $53.95 \pm 7.4 \mathrm{~kg}$, height of $160 \pm 5.4 \mathrm{~cm}$, and body mass index of $20.95 \pm 2.2 \mathrm{~kg} / \mathrm{m}^{2}$. Unpaired $t$-test was used to compare subject demographics in both treatment groups and there was no significant difference between the subjects' age, weight, height, or body mass index, with the $p$ values equal $0.90,0.95,0.86$, and 0.98 , respectively (Table 1 ).

Regarding PROMIS scores for pain level and NDI values for neck function, both groups showed a significant within-group improvement $(p<0.05)$ after the treatment. Between-group comparisons revealed nonsignificant pretreatment differences $(p>0.05)$ and significant post-treatment differences $(p<0.05)$ in favour of group I (Table 2$)$.

For cervical ROM (extension, right and left side bending), within-group comparisons showed a significant improvement $(p=0.0001)$ in both groups. Between-group comparisons revealed significant post-treatment differences $(p=$ 0.001 ) in favour of group I; before treatment, the differences between groups were nonsignificant $(p>0.05)$ (Table 3).

Table 1. Subjects' demographic characteristics in both groups

\begin{tabular}{|c|c|c|c|c|}
\hline & & & & \\
\hline & Group I & Group II & $t$ & $p$ \\
\hline Age (years) & $21.00 \pm 0.925$ & $21.07 \pm 1.60$ & -0.123 & 0.90 \\
\hline Weight (kg) & $54.06 \pm 8.32$ & $53.88 \pm 7.15$ & 0.052 & 0.95 \\
\hline Height $(\mathrm{cm})$ & $160 \pm 4.59$ & $160 \pm 6.05$ & 0.179 & 0.86 \\
\hline Body mass index $\left(\mathrm{kg} / \mathrm{m}^{2}\right)$ & $20.93 \pm 2.78$ & $20.96 \pm 1.98$ & -0.023 & 0.98 \\
\hline Number & 15 & 13 & & \\
\hline
\end{tabular}


Table 2. Changes in pain, pain threshold, and neck disability index in both groups

\begin{tabular}{|c|c|c|c|c|c|}
\hline & & Group I & Group II & Mann-Whitney & $p$ \\
\hline \multirow{4}{*}{ PROMIS } & Before treatment & $7.40 \pm 1.68$ & $3 \pm 0.91$ & 89.500 & $0.7216^{c}$ \\
\hline & After treatment & $2.60 \pm 0.91$ & $5.69 \pm 2$ & 6.000 & $<0.001^{a}$ \\
\hline & Wilcoxon value & 120.00 & 78.00 & & \\
\hline & $p$ & $0.001^{b}$ & $0.005^{b}$ & & \\
\hline \multirow{4}{*}{ PPT } & Before treatment & $3.47 \pm 0.7$ & $4.08 \pm 1.39$ & 72 & 0.25 \\
\hline & After treatment & $8.18 \pm 1.74$ & $6.36 \pm 1.62$ & 46 & $0.012^{a}$ \\
\hline & Wilcoxon value & -120.00 & -75.000 & & \\
\hline & $p$ & $0.0001^{\mathrm{b}}$ & $0.001^{b}$ & & \\
\hline \multirow{4}{*}{ NDI } & Before treatment & $25.15 \pm 4.5$ & $28.25 \pm 6.4$ & 1.498 & 0.15 \\
\hline & After treatment & $14 \pm 6.5$ & $18 \pm 3.5$ & 1.981 & $0.04^{a}$ \\
\hline & Wilcoxon value & 5.462 & 4.522 & & \\
\hline & $p$ & $0.0001^{\mathrm{b}}$ & $0.0001^{b}$ & & \\
\hline
\end{tabular}

Data expressed as mean \pm standard deviation and percentage of improvement

PROMIS - Patient-Reported Outcomes Measurement Information System, PPT - pressure pain threshold, NDI - neck disability index

a significant difference between both groups (Mann-Whitney test, $p<0.05$ ), ${ }^{\text {b }}$ significant difference within a group (Wilcoxon test, $p<0.05$ )

${ }^{c}$ non-significant difference

Table 3. Changes in cervical ROM in both groups

\begin{tabular}{|c|c|c|c|c|c|}
\hline & & Group I & Group II & $t$ & $p$ \\
\hline \multirow{4}{*}{ Extension } & Before treatment & $58.4 \pm 11.32$ & $50.45 \pm 1.731$ & 0.49 & 0.62 \\
\hline & After treatment & $70 \pm 5.4$ & $52.7 \pm 1.21$ & 5.31 & $0.001^{a}$ \\
\hline & $t$ & 6.277 & 7.784 & & \\
\hline & $p$ & $0.0001^{b}$ & $0.0001^{b}$ & & \\
\hline \multirow{4}{*}{ Right side bending } & Before treatment & $57.8 \pm 2.04$ & $56.4 \pm 1.5$ & 1.194 & 0.24 \\
\hline & After treatment & $63.3 \pm 1.59$ & $60.8 \pm 1.93$ & 12.3 & $0.0001^{a}$ \\
\hline & $t$ & 16.24 & 9.78 & & \\
\hline & $p$ & $0.0001^{b}$ & $0.0001^{b}$ & & \\
\hline \multirow{4}{*}{ Left side bending } & Before treatment & $57.9 \pm 1.94$ & $57.2 \pm 2.19$ & 2.14 & 0.64 \\
\hline & After treatment & $63.5 \pm 4.07$ & $60.9 \pm 1.86$ & 15.56 & $0.0001^{a}$ \\
\hline & $t$ & 7.427 & 4.57 & & \\
\hline & $p$ & $0.0001^{b}$ & $0.0001^{b}$ & & \\
\hline
\end{tabular}

Data expressed as mean \pm standard deviation and percentage of improvement

${ }^{a}$ significant difference between both groups (unpaired $t$-test, $p>0.05$ ), ${ }^{b}$ significant difference within a group (paired $t$-test, $p>0.05$ )

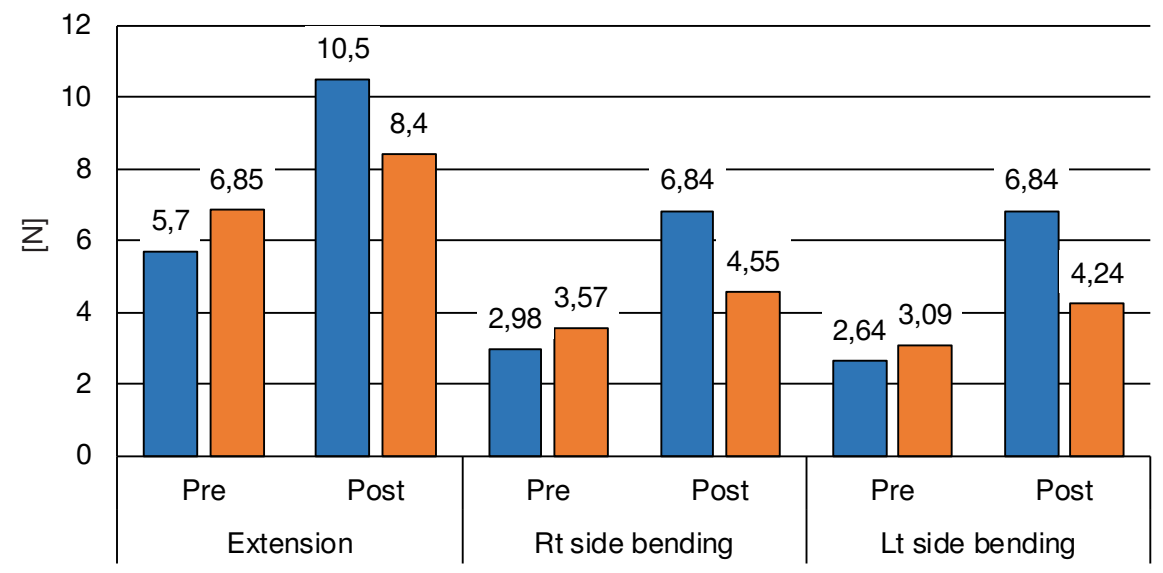


Isometric muscle strength in each movement was tested. For group I, extension showed an increase from an average $5.70 \pm 2.28$ to $10.5 \pm 2.4$ ( $p=0.001$, paired $t$-test), while in group II, the value increased from an average $6.85 \pm 3.0$ to $8.4 \pm 2.1$ and this was a nonsignificant difference $(p=0.14$, paired $t$-test). Between-group comparisons revealed a nonsignificant pre-treatment difference ( $p=0.26$, unpaired $t$-test) and a significant post-treatment difference $(p=0.02)$ in favour of group I (Figure 1). Regarding within-group comparisons for the right and left side bending, group I presented a significant improvement $(p=0.001$ and 0.0001 , respectively, paired $t$-test) as it improved from $2.98 \pm 0.79$ to 6.84 \pm 1.55 in right bending and changed from $2.64 \pm 0.94$ to $6.84 \pm 1.55$ in left bending. In group II, right bending showed a nonsignificant difference ( $p=0.2$, paired $t$-test) and changed from $3.57 \pm 1.73$ to $4.55 \pm 2.15$, while left bending demonstrated a very weakly significant difference $(p=0.07$, paired $t$-test) and changed from $3.09 \pm 1.58$ to $4.24 \pm 1.68$. Betweengroup comparisons revealed significant post-treatment differences ( $p=0.003$ and 0.001 , respectively, unpaired $t$-test) for right and left bending in favour of group $I$, and nonsignificant pre-treatment differences ( $p=0.24$ and 0.9 , respectively, unpaired $t$-test) for both movements.

Two-way ANOVA was conducted to examine the interaction between subject group and time span. For pain, there was a nonsignificant interaction between the groups and assessment time for pain level $(F=0.46, p=0.50)$. On the other hand, time showed a significant reduction when measured after 3 weeks as compared with the beginning of the study $(p=0.0005)$ but there was no difference between groups $(p=0.50)$. For pain threshold, there was a nonsignificant interaction between the groups and assessment time for pain threshold $(F=0.92, p=0.34)$. On the other hand, time showed a significant reduction when measured after 3 weeks as compared with the beginning of the study $(p=0.0001)$ but there was no difference between groups $(p=0.88)$. For NDI, there was a significant interaction between the groups and assessment time for neck function ( $F=10.31, p=0.002)$. For ROM, there was a nonsignificant interaction between the groups and assessment time with respect to extension, right side bending, and left side bending $(F=0.41, p=0.53 ; F=2.13$, $p=0.15 ; F=2.88, p=0.09)$. Regarding the isometric muscle strength, there was a significant interaction between the groups and assessment time with respect to extension, right side bending, and left side bending muscle strength ( $F=5.43$, $p=0.02 ; F=6.13, p=0.02 ; F=4.37, p=0.04)$.

Normality test was applied for all dependent variables in the 2 groups, using the Shapiro-Wilk test. All variables showed normal distribution in both groups $(p>0.05)$, except for pain, left side bending ROM, and right and left side bending isometric muscle strength in the control group.

\section{Discussion}

The study was conducted among 28 female students complaining of neck pain, to investigate the effect of microcurrent electrical stimulation on MTrPs of the upper fibre of the trapezius. The outcome measures were in terms of pain level: neck function improvement, and ROM and isometric muscle strength increase in subjects with unilateral MTrPs.

Both groups received a standard treatment program consisting of ischaemic compression, stretching and strengthening exercises. The results showed a significant decrease in pain level and NDI, and increase in pressure pain threshold. Ischaemic compression on the trigger points of the trapezius muscle significantly improve the pressure pain thresh- old values, trigger point sensitivity pain intensity [30], cervical active ROM [31], and neck muscle strength [32]. Furthermore, stretching exercises permit recovery of functional muscle length, stress relief, improvement in postural realignment, and freedom and awareness of movement [33, 34]. In turn, specific strength training is able to decrease pain and disability, as well as increase strength in the muscles of the neck [35-37]. A combination of stretching and strengthening encourages the joint and muscle mechanoreceptors and proprioceptors [38]. This would reduce pain sensation via the inhibitory effects of Golgi tendon organs, which decrease the motor neuronal discharges, leading to relaxation of the musculotendinous unit by resetting its resting length and modification of Pacinian corpuscles [39].

Group I received additional treatment by microcurrent electrical stimulation and showed significant differences in comparison with group II (control group). Microcurrent therapies are now being increasingly recognized as an adjunct for pain relief and autonomic nervous system regulation [40, 41]. The results obtained in group I can be attributed to microcurrent mimicking human bio-cellular communications that regulate the autonomic nervous system, which results in body wide therapeutic benefits [40]. Furthermore, microcurrent activates reductions in inflammatory cytokines and increases $\beta$-endorphin release [42], leading to prolonged pain relief after microcurrent electrical stimulation.

In the current study, microcurrent therapy was combined with traditional treatment. This is consistent with Bonacci and Higbie [43], who reported that the use of microcurrent alone was not effective in reducing pain and increasing muscle function following an exhaustive bout of eccentric exercises.

Thereby, the augmented effect observed in group I is a result of microcurrent therapy combined with traditional treatment. This is also in agreement with a study by McMakin [44], who reported that microcurrent combined with manual therapy (chiropractic) reduced pain and increased ROM after the first 20-minute session in patients with persistent chronic MTrPs, and concluded that microcurrent therapy made chiropractic very effective in patients having persistent chronic MTrPs. The same observation was noted when hot packs, transcutaneous electrical nerve stimulation, and deep cervical flexors strengthening exercise were applied with or without Mulligan upper cervical manual traction in cervicogenic headache cases in terms of NDI and upper cervical rotation ROM [45].

In the present study, the improvement of pain relief by using microcurrent electrical stimulation may be attributed to the advantage of this modality being subthreshold, and hence the side effects such as tingling sensation and paraesthesia that can be seen in some patients after the application of other electrical stimulation techniques, as transcutaneous electrical nerve stimulation, are absent. This is in line with the results obtained by Saranya et al. [46], who demonstrated that the group with microcurrent electrical stimulation showed more improvement compared with the group of transcutaneous electrical nerve stimulation.

The results of this study are consistent with those achieved by Park et al. [47], who investigated the effect of microcurrent electrical stimulation on myofascial neck pain and stiffness and found that the microcurrent electrical neuromuscular stimulation improved pressure pain threshold, pain intensity, and shear wave velocity in chronic myofascial pain syndrome in upper trapezius muscles. Furthermore, the significant improvement in cervical ROM, NDI, and pain level due to the combination of microcurrent electrical stimulation with stretching and strengthening exercises is supported by a simi- 
lar conclusion concerning a multimodal approach of electrotherapy or myofascial release therapy and traditional therapeutic exercises in treating chronic mechanical neck pain [48].

\section{Limitations}

The psychological tangent to myofascial pain syndrome may have effect on the improvement of the patient, and hence the study might include a questionnaire on the patient's anxiety and stress scale, as well as the pre- and post-treatment effect on quality of life.

\section{Conclusions}

It was concluded that the combination of microcurrent therapy and traditional treatment was effective in managing patients with myofascial pain syndrome characterized by neck pain and dysfunction. This effectiveness concerned decreased pain and NDI, with increased pain threshold, cervical $\mathrm{ROM}$, and isometric muscle strength, whereas traditional treatment alone was a less effective modality. Thus, both modalities can be used as alternative conservative therapy rather than medications that have numerous side effects.

\section{Disclosure statement}

No author has any financial interest or received any financial benefit from this research.

\section{Conflict of interest}

The authors state no conflict of interest.

\section{References}

1. Fejer R, Kyvik KO, Hartvigsen J. The prevalence of neck pain in the world population: a systematic critical review of the literature. Eur Spine J. 2006;15(6):834848; doi: 10.1007/s00586-004-0864-4.

2. Travell JG, Simons DG. Myofascial pain and dysfunction: the trigger point manual. Williams \& Wilkins; 1992.

3. Leite FMG, Atallah ÁN, El Dib R, Grossmann E, Januzzi E, Andriolo RB, et al. Cyclobenzaprine for the treatment of myofascial pain in adults. Cochrane Database Syst Rev. 2009;2009(3):CD006830; doi: 10.1002/14651858. CD006830.pub3.

4. Wheeler AH, Aaron GW. Muscle pain due to injury. Curr Pain Headache Rep. 2001;5(5):441-446; doi: 10.1007/ s11916-001-0055-5.

5. Dommerholt J, Bron C, Franssen J. Myofascial trigger points: an evidence-informed review. J Man Manip Ther. 2006;14(4):203-221; doi: 10.1179/106698106790 819991.

6. Simons DG, Stolov WC. Microscopic features and transient contraction of palpable bands in canine muscle. Am J Phys Med. 1976;55(2):65-88.

7. Jafri MS. Mechanisms of myofascial pain. Int Sch Res Notices. 2014;2014:523924;doi:10.1155/2014/523924.

8. Bullock JD. Relative afferent pupillary defect in the "better" eye. J Clin Neuroophthalmol. 1990;10(1):45-51; doi: 10.3109/01658109008997261.

9. Celik D, Mutlu EK. Clinical implication of latent myofascial trigger point. Curr Pain Headache Rep. 2013;17(8):353; doi: 10.1007/s11916-013-0353-8.

10. Hoving JL, Koes BW, de Vet HCW, van der Windt DAWM, Assendelft WJJ, van Mameren $\mathrm{H}$, et al. Manual therapy, physical therapy, or continued care by a general practitioner for patients with neck pain. A randomized, con-
10.7326/0003-4819-136-10-200205210-00006.

11. Jette AM, Delitto A. Physical therapy treatment choices for musculoskeletal impairments. Phys Ther. 1997;77(2): 145-154; doi: 10.1093/ptj/77.2.145.

12. Ravichandran P, Ponni HK, Aseer PAL. Effectiveness of ischemic compression on trapezius myofascial trigger points in neck pain. Int J Physiother. 2016;3(2):186192; doi: 10.15621/ijphy/2016/v3i2/94883.

13. Denegar CR, Saliba E, Saliba S. Therapeutic modalities for musculoskeletal injuries, $4^{\text {th }}$ ed. Champaign: Human Kinetics; 2015.

14. Xu Y-M, Ge H-Y, Arendt-Nielsen L. Sustained nociceptive mechanical stimulation of latent myofascial trigger point induces central sensitization in healthy subjects. J Pain. 2010;11(12):1348-1355; doi: 10.1016/j.jpain.2010.03.010.

15. Rodríguez-Fernández ÁL, Garrido-Santofimia V, GüeitaRodríguez J, Fernández-de-las-Peñas $\mathrm{C}$. Effects of bursttype transcutaneous electrical nerve stimulation on cervical range of motion and latent myofascial trigger point pain sensitivity. Arch Phys Med Rehabil. 2011; 92(9):1353-1358; doi: 10.1016/j.apmr.2011.04.010.

16. Mercola JM, Kirsch DL. The basis for microcurrent electrical therapy in conventional medical practice. J Adv Med. 1995;8(2):107-120.

17. Vodovnik L, Karba R. Treatment of chronic wounds by means of electric and electromagnetic fields. Part 1. Literature review. Med Biol Eng Comput. 1992;30(3):257266; doi: 10.1007/BF02446963.

18. Cook KF, Jensen SE, Schalet BD, Beaumont JL, Amtmann D, Czajkowski S, et al. PROMIS measures of pain, fatigue, negative affect, physical function, and social function demonstrated clinical validity across a range of chronic conditions. J Clin Epidemiol. 2016;73:89-102; doi: 10.1016/j.jclinepi.2015.08.038.

19. Kinser AM, Sands WA, Stone MH. Reliability and validity of a pressure algometer. J Strength Cond Res. 2009;23(1): 312-314; doi: 10.1519/jsc.0b013e31818f051c.

20. Han TR, Kim JH, Chun MH, Choi KH. Pain threshold using a pressure algometer in normal Korean young adults. $\mathrm{J}$ Korean Acad Rehabil Med. 1994;18(2):219-226.

21. Fischer AA. Pressure threshold meter: its use for quantification of tender spots. Arch Phys Med Rehabil. 1986; 67(11):836-838; doi: 10.5555/uri:pii:0003999386901802.

22. Delaney GA, McKee AC. Inter- and intra-rater reliability of the pressure threshold meter in measurement of myofascial trigger point sensitivity. Am J Phys Med Rehabil. 1993;72(3):136-139; doi: 10.1097/00002060-199306000 -00005 .

23. Vernon $\mathrm{H}$. The neck disability index: state-of-the-art, 1991-2008. J Manipulative Physiol Ther. 2008;31(7): 491-502; doi: 10.1016/j.jmpt.2008.08.006.

24. MacDermid JC, Walton DM, Avery S, Blanchard A, Etruw E, McAlpine C, et al. Measurement properties of the neck disability index: a systematic review. J Orthop Sports Phys Ther. 2009;39(5):400-417; doi: 10.2519/ jospt.2009.2930.

25. Pearson I, Reichert A, De Serres SJ, Dumas J-P, Côté JN. Maximal voluntary isometric neck strength deficits in adults with whiplash-associated disorders and association with pain and fear of movement. J Orthop Sports Phys Ther. 2009;39(3):179-187; doi: 10.2519/jospt.2009. 2950.

26. Chiu TTW, Lam T-H, Hedley AJ. Maximal isometric muscle strength of the cervical spine in healthy volunteers. Clin Rehabil. 2002;16(7):772-779; doi: 10.1191/ 0269215502 cr552oa. 
27. Audette I, Dumas J-P, Côté JN, De Serres SJ. Validity and between-day reliability of the cervical range of motion (CROM) device. J Orthop Sports Phys Ther. 2010; 40(5):318-323; doi: 10.2519/jospt.2010.3180.

28. Tousignant M, Smeesters C, Breton A-M, Breton É, Corriveau $\mathrm{H}$. Criterion validity study of the cervical range of motion (CROM) device for rotational range of motion on healthy adults. J Orthop Sports Phys Ther. 2006; 36(4):242-248; doi: 10.2519/jospt.2006.36.4.242.

29. Chao YW, Lin JJ, Yang JL, Wang WTJ. Kinesio taping and manual pressure release: short-term effects in subjects with myofascial trigger point. J Hand Ther. 2016; 29(1):23-29; doi: 10.1016/j.jht.2015.10.003.

30. Jagad BH, Jagad KB. Effects of ischemic compression on the trigger points in the upper trapezius muscle. Indian J Physiother Occup Ther. 2013;7(1):99-104.

31. Montañez-Aguilera FJ, Valtueña-Gimeno N, Pecos-Martín D, Arnau-Masanet R, Barrios-Pitarque C, BoschMorell F. Changes in a patient with neck pain after application of ischemic compression as a trigger point therapy. J Back Musculoskelet Rehabil. 2010;23(2):101-104; doi: 10.3233/BMR-2010-0255.

32. Cagnie B, Dewitte V, Coppieters I, Van Oosterwijck J, Cools A, Danneels L. Effect of ischemic compression on trigger points in the neck and shoulder muscles in office workers: a cohort study. J Manipulative Physiol Ther. 2013;36(8):482-489; doi: 10.1016/j.jmpt.2013.07.001.

33. Anders C, Sprott H, Scholle HC. Surface EMG of the lumbar part of the erector trunci muscle in patients with fibromyalgia. Clin Exp Rheumatol. 2001;19(4):453-455.

34. De Lorena SB, de Lima MCC, Ranzolin A, Pinto Duarte ÂLB. Effects of muscle stretching exercises in the treatment of fibromyalgia: a systematic review. Rev Bras Reumatol. 2015;55(2):167-173; doi: 10.1016/j.rbr.2014.08. 015.

35. Andersen LL, Kjaer M, Søgaard K, Hansen L, Kryger Al, Sjøgaard G. Effect of two contrasting types of physical exercise on chronic neck muscle pain. Arthritis Care Res. 2008;59(1):84-91; doi: 10.1002/art.23256.

36. Zebis MK, Andersen LL, Pedersen MT, Mortensen P, Andersen $\mathrm{CH}$, Pedersen MM, et al. Implementation of neck/ shoulder exercises for pain relief among industrial workers: a randomized controlled trial. BMC Musculoskelet Disord. 2011;12(1):205; doi: 10.1186/1471-2474-12-205.

37. Battecha KH, Abdel Raoof NA, Kamel DM, Tantawy SA. The effect of cranio-cervical flexion training and rest break on neck pain and functional performance in visual display unit users. Biosci Res. 2018;15(4):3708-3717.

38. Chaitow L, DeLany J. Clinical application of neuromuscular techniques: the upper body, $2^{\text {nd }}$ ed. Elsevier Health Sciences; 2008.

39. Phadke A, Bedekar N, Shyam A, Sancheti P. Effect of muscle energy technique and static stretching on pain and functional disability in patients with mechanical neck pain: a randomized controlled trial. Hong Kong Physiother J. 2016;35:5-11; doi: 10.1016/j.hkpj.2015.12.002.

40. Chevalier A, Armstrong K, Norwood-Williams C, Gokal R. $D C$ electroacupuncture effects on scars and sutures of a patient with postconcussion pain. Med Acupunct. 2016; 28(4):223-229; doi: 10.1089/acu.2016.1188.

41. McMakin CR. Microcurrent therapy: a novel treatment method for chronic low back myofascial pain. J Bodyw Mov Ther. 2004;8(2):143-153; doi: 10.1016/j.jbmt.2003. 12.006 .

42. McMakin CR, Gregory WM, Phillips TM. Cytokine changes with microcurrent treatment of fibromyalgia associ- ated with cervical spine trauma. J Bodyw Mov Ther. 2005; 9(3):169-176; doi: 10.1016/j.jbmt.2004.12.003.

43. Bonacci JA, Higbie EJ. Effects of microcurrent treatment on perceived pain and muscle strength following eccentric exercise. J Athl Train. 1997;32(2):119-123.

44. McMakin C. Microcurrent treatment of myofascial pain in the head, neck, and face. Top Clin Chiro. 1998;5(1): 29-35.

45. Khalil MA, Alkhozamy $H$, Fadle S, Hefny AM, Ismail MA. Effect of Mulligan upper cervical manual traction in the treatment of cervicogenic headache: a randomized controlled trial. Physiother Quart. 2019;27(4):13-20; doi: 10.5114/pq.2019.87738.

46. Saranya B, Ahmed J, Shenoy N, Ongole R, Sujir N, Natarajan S. Comparison of transcutaneous electric nerve stimulation (TENS) and microcurrent nerve stimulation (MENS) in the management of masticatory muscle pain: a comparative study. Pain Res Manag. 2019;2019: 8291624; doi: 10.1155/2019/8291624.

47. Park JW, Kwak J, Lee S, Lee S. Microcurrent electrical neuromuscular stimulation to improve myofascial neck pain and stiffness. Ann Phys Rehabil Med. 2018; 61(Suppl.):e108; doi: 10.1016/j.rehab.2018.05.232.

48. El-Gendy MH, Lasheen YR, Rezkalla WKS. Multimodal approach of electrotherapy versus myofascial release in patients with chronic mechanical neck pain: a randomized controlled trial. Physiother Quart. 2019;27(4):6-12; doi: $10.5114 /$ pq.2019.87735. 